\title{
Simulation Studies of the Effect of Cavity on the Natural Frequency of an Enterolobium Cyclocarpum Tree
}

\author{
Radon Dhelika, Wahyu Nirbito and Anantama Karis \\ Department of Mechanical Engineering, Faculty of Engineering, \\ Universitas Indonesia (UI) Kampus, 16424 Depok, Indonesia \\ radon@eng.ui.ac.id, +6282113334825
}

\begin{abstract}
Tree is an important part of urban ecology. Therefore, the condition of trees from time to time should be routinely monitored in order to avoid the case of falling trees that often take casualties. There have been several methods to detect such defects as an early indicator of tree's condition for example by acoustic tomography intrusive indentation, etc. This study proposes a new detection method by assessing changes in natural frequency of a tree when a defect is present. The selected tree is Enterolobium cyclocarpum (Bahasa Indonesia: Sengon Buto) and the defect in the form of cavities is set to be the focal point. Natural frequencies are obtained with the help of an FEM Software. Several simulations are conducted under different geometrical parameters of a cylindrical-shaped cavity in the tree model. With diameter at breast height of $240 \mathrm{~mm}$ and height of $7 \mathrm{~m}$, the natural frequency obtained is $3.19 \mathrm{~Hz}$ and the maximum change that occurs with the presence of cavities recorded in this study is $3.9 \%$. The results show a potential for the use of natural frequency as a way for tree's condition monitoring.
\end{abstract}

Key words: Vibration, modal analysis, tree, condition monitoring, FEM Software, Indonesia

\section{INTRODUCTION}

Tree is an important component in every urban area because it has a great influence on the quality of the environment. Therefore, the condition of the tree becomes a matter of great concern. Poor physical strength of the tree can cause problems, especially, failures such as falling trees which potentially cause damages or personal injuries.

The incidence of falling trees can be triggered by many factors, ranging from external factors such as wind internal factors of the tree such as poor growth form, to combination of factors that affect the tree. There are 7 types of defects that can be identified on trees including decayed wood, crack and root problems (Pokorny et al., 2003). The defect or damage on a tree can be used as a sign to predict the potential failure of the tree in the future. Although, healthy trees can also collapse, trees with defect or damage have a greater potential to collapse. Therefore, it is necessary to identify the condition of a tree, so that, the potential collapse of the tree can be well predicted.

There are various methods to identify the condition of a tree, from conventional methods by inspecting the physical condition of the tree or by the help of various tools such as the well-spread acoustic tomography. The conventional method, i.e., physical inspection is the easiest method to use but it has many limitations. Acoustic method is a method that is commonly used by measuring wave transmission time from the sensors which are installed around the tree trunk (Socco et al., 2004). This method produces tomographic image depicting the physical condition of the tree (Bucur, 2003). However, data retrieval by using this method is not easy because measurement should be done along the tree's height. Previous studies have also used a variety of sensors including rotary of linear potentiometers connected to trees by thin wires (Milne, 1991), accelerometers (White et al., 1976) and prism-based systems (Hassinen et al., 1998). Those sensors have been proven to provide data to help identify the condition of a tree. However, each of those sensors have its own limitations and some of them are expensive.

In this research, the use of vibration analysis is proposed to identify the condition of a tree. This method is inspired from the well-known technique of machine condition monitoring which is more commonly implemented in industry for detecting the condition of rotating equipments such as pumps and turbines. By measuring the natural frequency of the system (and other modal parameters), many aspects related to the condition of the machines can be identified.

Corresponding Author: Radon Dhelika, Department of Mechanical Engineering, Faculty of Engineering, Universitas Indonesia (UI) Kampus, 16424 Depok, Indonesia radon@eng.ui.ac.id, +6282113334825 
Previously many research works on vibration analysis on trees has been abundant, however, the focal point has been different such as for optimizing the process of harvesting by vibration (Miles et al., 1981; Castro-Garcia et al., 2011; Sola-Guirado et al., 2014) and for understanding the mechanical stability and dynamic behavior of trees under wind loads, especially for the purpose of urban trees management (Telewski, 1995; Kerzenmacher and Gardiner, 1998; Spatz and Bruechert, 2000; Moore and Maguire, 2005). In this study, defects, especially, cavities, on a tree are considered and their effect on changes in natural frequencies are evaluated.

\section{MATERIALS AND METHODS}

Theory and modeling of the tree: The natural frequency of the tree is predicted by modeling it as a cantilever beam that oscillates under free vibration. Previous researches had also taken this approach by using a simple model of a tapered beam made of a homogeneous material (Spatz and Bruechert, 2000). The free vibration equation of motion is given by the following general form of partial differential equation (Moore and Maguire, 2005):

$$
\frac{\partial^{2}}{\partial z^{2}}\left(\operatorname{EI}(z) \frac{\partial^{2} y}{\partial z^{2}}\right)+\rho A(z) \frac{\partial^{2} y}{\partial t^{2}}
$$

Where:

$\mathrm{y}=$ The displacement at time $\mathrm{t}$

$z=$ The distance from the fixed end of the beam

$\mathrm{E}=$ Young's modulus

$\rho=$ Wood density

The second moment of area I of the trunk cross section and its area $\mathrm{A}$ are both assumed to be functions of distance $z$, so that, this general equation can cater to the case of a tapered beam.

With proper application of boundary conditions, Eq. 1 can be solved to give us the natural frequency of the vibration. Qualitatively, it has been understood generally (Moore and Maguire, 2005) that the value of the natural frequency is a function of EI, $\rho$ (Wood's density), A (cross-sectional area of the trunk) and $\mathrm{H}$ (height of the tree).

Therefore, the natural frequency will be affected by several variables of geometry and its material properties such as L (strength of the beam), I (Inertia), k (stiffness), E (Young's modulus).

Modeling: The object of this research is set to Enterolobium cyclocarpum tree (Bahasa Indonesia: Sengon buto) based on the real need in the campus of

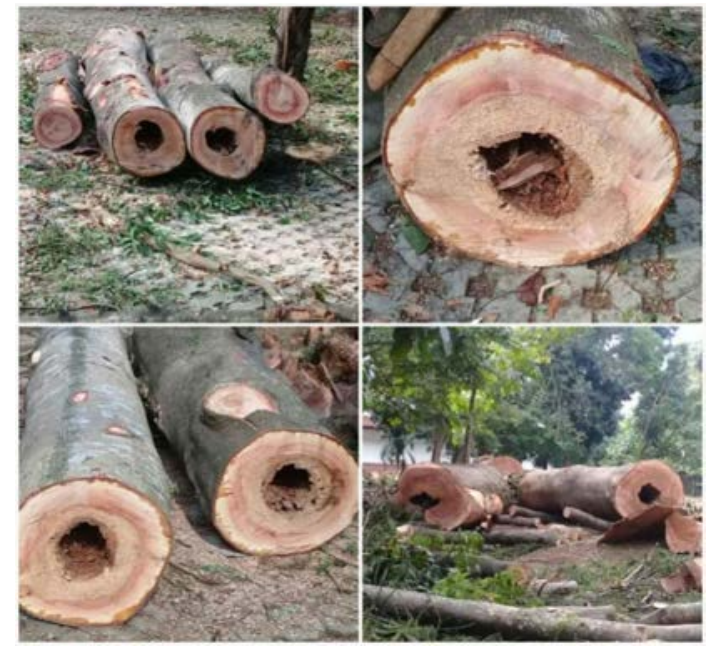

Fig. 1: Defects in the form of cavity in an enterolobium cyclocarpum tree in Universitas Indonesia. (Photos courtesy of Anom Bowolaksono, OSHE Unit, Universitas Indonesia)

Universitas Indonesia. Enterolobium cyclocarpum is known as a species native to tropical regions. According to the information from Occupational Safety, Health and Environmental (OSHE) Unit of Universitas Indonesia, due to the large population of Enterolobium cyclocarpum trees in the campus area, there have been a lot of failure incidences, especially, caused by external factors such as strong wind during rainy season. The large number of incidences involving Enterolobium cyclocarpum trees are also due to the fact that the existing trees in the campus are already past their age limit of $20-25$ years. This evidently had caused cavities to form from within the trees that contribute to the likelihood of failure. Figure 1 shows defects found in Enterolobium cyclocarpum trees in a form of cavities observed by OSHE Unit in the campus of Universitas Indonesia.

The research was conducted using a simplified Enterolobium cyclocarpum tree model and then simulated by finite element method (Moore and Maguire, 2008; Sellier et al., 2006) to predict the natural frequency of the model. Each tree model has a diameter of $260 \mathrm{~mm}$ at the base of the tree and $240 \mathrm{~mm}$ at the Breast Height (BH) as shown in Fig. 2a. Information related to material properties (such as density and Young's modulus) of Enterolobium cyclocarpum tree are obtained from The Wood Database. As per the observed cavities in Fig. 1 for the sake of simplicity, the cavity in the tree model is designed to be shaped cylindrical with certain parameters such as its vertical position $\left(\mathrm{z}_{\text {carity }}\right)$, diameter $\left(\mathrm{d}_{\text {carity }}\right)$ and length $\left(1_{\text {caxity }}\right)$. 

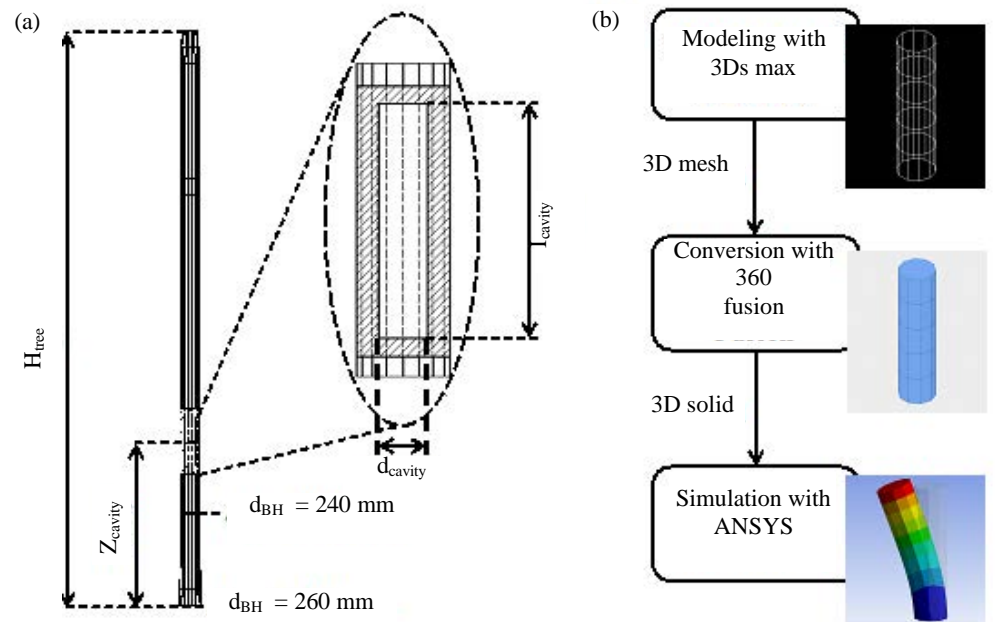

Fig. 2: a) Modeling of the tapered tree with a cylindrical-shaped cavity and b) The process of modeling work and the results obtained from each software used

\begin{tabular}{|c|c|c|c|c|c|c|}
\hline $\begin{array}{l}\text { Simulation } \\
\text { number }\end{array}$ & $\begin{array}{l}\text { Height of tree, } \\
\mathrm{H}_{\text {tree }}(\mathrm{m})\end{array}$ & $\begin{array}{l}\text { Vertical position of cavity, } \\
Z_{\text {rasity }}(\mathrm{m})\end{array}$ & $\begin{array}{l}\text { Diameter of cavity, } \\
\mathrm{d}_{\text {casity }}(\mathrm{mm})\end{array}$ & $\begin{array}{l}\text { Length of cavity, } \\
1_{\text {casity }}(\mathrm{mm})\end{array}$ & Parameter varied & Results \\
\hline 1 & $\begin{array}{l}5 \\
6 \\
7 \\
8 \\
9 \\
10\end{array}$ & - & - & - & Height of tree $\left(\mathrm{H}_{\text {tree }}\right)$ & Figure 3 \\
\hline 2 & 7 & $\begin{array}{l}1 \\
2 \\
3 \\
4 \\
5 \\
6\end{array}$ & 130 & 600 & Vertical position of cavity $\left(\mathrm{z}_{\text {carity }}\right)$ & Figure 5a \\
\hline 3 & 7 & 1 & $\begin{array}{l}130 \\
110 \\
90 \\
70 \\
50 \\
30\end{array}$ & 600 & Diameter of cavity $\left(\mathrm{d}_{\text {carity }}\right)$ & Figure $5 b$ \\
\hline 4 & 7 & 2 & 130 & $\begin{array}{l}500 \\
750 \\
1000 \\
1250 \\
1500 \\
1750 \\
2000 \\
\end{array}$ & Length of cavity $\left(l_{\text {cavity }}\right)$ & Figure $5 \mathrm{c}$ \\
\hline
\end{tabular}

Modeling was done using the aid of 3DS Max Software, the tree was modeled in accordance with predetermined parameters. The model generated from 3DS Max was still in mesh form, so, a conversion to solid was also performed using 360 Fusion software. After getting the final model, ANSYS finite element software package was used to predict the natural frequency. The modeling work process is shown in Fig. $2 \mathrm{~b}$.

In this research, four different simulations with varying parameters were carried out. Detail information for each of them is tabulated in Table 1. In the first simulation, the geometrical parameter varied was the height of the tree model $\left(\mathrm{H}_{\text {tree }}\right)$ without introducing the cavity yet. This approach was done in the first step for the purpose of validation of this simulation process. Based on observations, the height of Enterolobium cyclocarpum trees encountered varies from 5-7 m. Therefore, the height of the tree model used was $5-10 \mathrm{~m}$.

For the next three simulations, the aim was to determine the effect of cavities on the changes of natural frequencies. Simulation was carried out to the tree model having the same height, i.e., $7 \mathrm{~m}$ which was added a defect in the form of cavity in the tree. In this modeling, the cavity was modeled as a cylindrical shape within the tree's circumference with its geometrical parameters varied. As shown in Fig. 2a, the parameters varied were its 
vertical position $\left(\mathrm{z}_{\text {carity }}\right)$, its diameter $\left(\mathrm{d}_{\text {caxity }}\right)$ and its length $\left(1_{\text {carity }}\right)$. In the second simulation, (parameter varied was vertical position of cavity $\left(\mathrm{z}_{\text {carity }}\right)$ ), the tree model was given a cylindrical cavity with $\mathrm{d}_{\text {carity }}$ of $130 \mathrm{~mm}$ and $1_{\text {carity }}$ of $600 \mathrm{~mm}$ whereas its vertical position, $z_{\text {canty }}$ was varied from 1-6 $\mathrm{m}$ with an increment of $1 \mathrm{~m}$. In the third simulation (parameter varied was diameter of cavity $\left(\mathrm{d}_{\mathrm{caxity}}\right)$ ), the cavity was set with a vertical position of $1 \mathrm{~m}$ with its $d_{\text {caxity }}$ varied from $130-30 \mathrm{~mm}$ with a decrement of $20 \mathrm{~mm}$. Since, the diameter of the base, $\mathrm{d}_{\text {base }}$ was set at $260 \mathrm{~mm}$, a d $\mathrm{d}_{\text {cavity }}$ of $130 \mathrm{~mm}$ corresponds to a tree with half of its circumference being defective with a cavity. In the forth simulation, (parameter varied was length of cavity $\left(1_{\text {cavity }}\right)$ ), the cavity was positioned vertically at $2 \mathrm{~m}$ with a diameter of $130 \mathrm{~mm}$ and values of $1_{\text {carity }}$ varied from $500-2000 \mathrm{~mm}$ with an increment of $250 \mathrm{~mm}$.

\section{RESULTS AND DISCUSSION}

To validate the accuracy of the model and the simulation process an initial simulation was performed in which the height of the tree model was varied. The natural frequency used was the first mode frequency of the simulation result. Results obtained are shown in Table 2 and Fig. 3. Based on Table 2, it can be seen that the natural frequency of the tree model decreases as the height increases. Additionally, from the plot of the curve in Fig. 3, curve fitting was carried out which resulted in the value of power coefficient of -2.036 . This value is arguably very close to the power coefficient of -2 obtained from the general equations in the case of a cantilever beam that oscillates under free vibration. A slight error is thought to result from the tapered geometry of the tree model. Results obtained from the first simulation show that the method performed sports a scientific validity, since, it corresponds to the general theory of vibration of a cantilever beam. Typical motion of the first mode free vibration of the Enterolobium cyclocarpum tree model is given in Fig. 4 with color indicating the amount of displacement.

For subsequent simulations in which cavities with various geometrical parameters were introduced to the tree model, all results are given in Table 3-5 and Fig. 5a-c. In the second simulation whose graph is shown in Fig. 5a, the natural frequencies are observed to be able to go higher and lower than that of a healthy tree. This means that depending on the vertical position of the cavity, the natural frequency can change in both directions. From this particular simulation with the height of the tree model set at $7 \mathrm{~m}$, the value of natural frequency is below that of the healthy tree when the cavity was positioned at 1 or $2 \mathrm{~m}$ with maximum decrease is approximately $1.2 \%$. On the other hand when the cavity

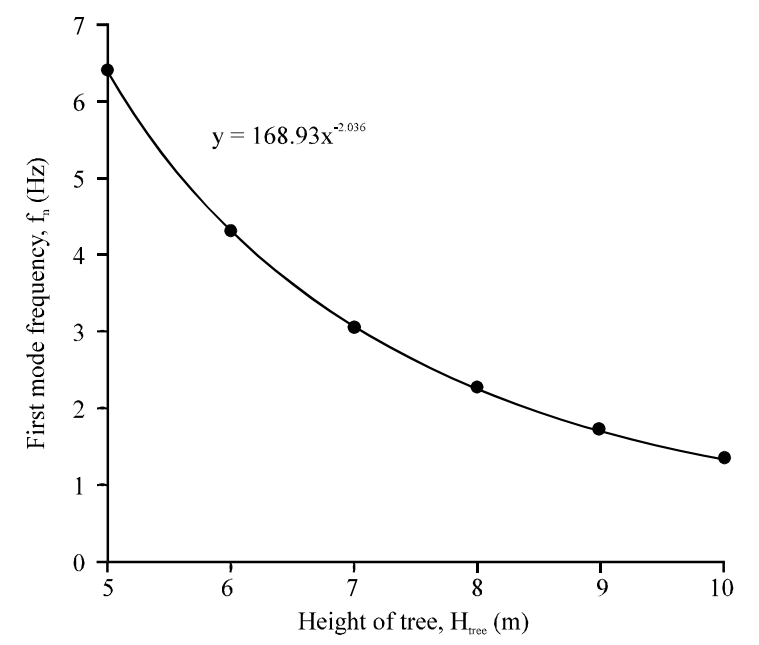

Fig. 3: Graph of the first mode natural frequencies of the tree model with height variations

Table 2: Simulation results of natural frequencies of the tree model with height variations

\begin{tabular}{lc}
\hline Height of tree, $\mathrm{H}_{\text {tree }}(\mathrm{m})$ & First mode frequency $(\mathrm{Hz})$ \\
\hline 5 & 6.3876 \\
6 & 4.4069 \\
7 & 3.1924 \\
8 & 2.4533 \\
9 & 1.9192 \\
10 & 1.5615 \\
\hline
\end{tabular}

Table 3: Simulation results with varied vertical position of cavity

\begin{tabular}{lc}
\hline Vertical position of cavity, $\mathrm{Z}_{\text {rasity }}(\mathrm{m})$ & First mode frequency $(\mathrm{Hz})$ \\
\hline 1 & 3.1542 \\
2 & 3.1730 \\
3 & 3.1937 \\
4 & 3.2215 \\
5 & 3.2611 \\
6 & 3.3166 \\
\hline
\end{tabular}

Table 4: Varied diameter of cavity

\begin{tabular}{lc}
\hline Diameter of cavity, $\mathrm{d}_{\text {ravity }}(\mathrm{mm})$ & First mode frequency $(\mathrm{Hz})$ \\
\hline 30 & 3.1924 \\
50 & 3.1917 \\
70 & 3.1895 \\
90 & 3.1843 \\
110 & 3.1738 \\
130 & 3.1542 \\
\hline
\end{tabular}

Table 5: Varied length of cavity in the tree model

\begin{tabular}{lc}
\hline Length of cavity, $1_{\text {cavity }}(\mathrm{mm})$ & First mode frequency (Hz) \\
500 & 3.1759 \\
750 & 3.1686 \\
1000 & 3.1612 \\
1250 & 3.1542 \\
1500 & 3.1472 \\
1750 & 3.1401 \\
2000 & 3.1333 \\
\hline
\end{tabular}

was located at a higher vertical position starting from approximately mid point of the tree model, the natural frequency reaches higher value than that of the healthy tree. For vertical position of $6 \mathrm{~m}$, the increase is observed to be around $3.9 \%$. 
(a)

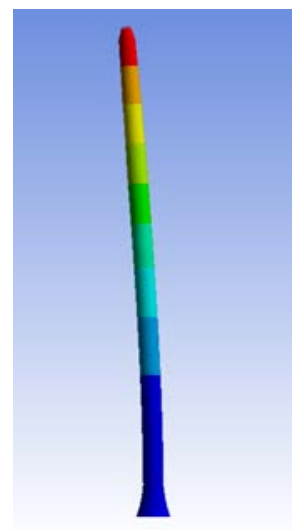

(b)

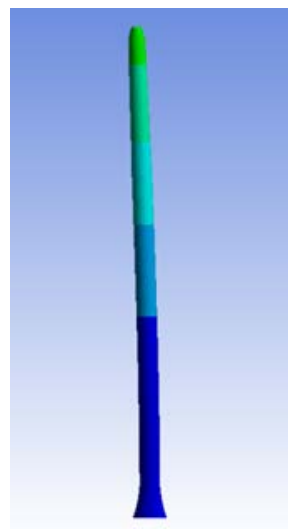

(c)

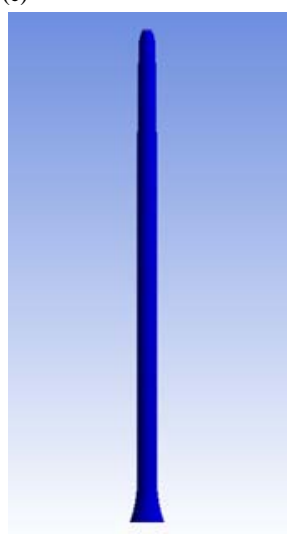

(d)

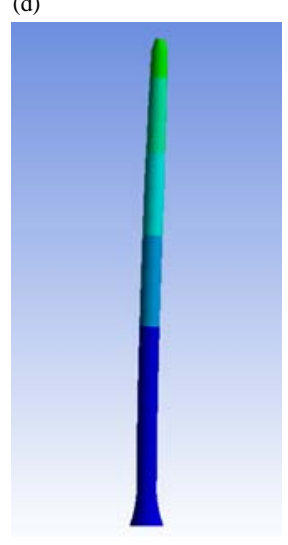

(e)

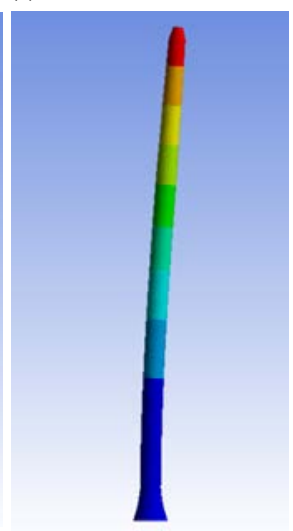

Fig. 4a-e): Typical motion of the first mode vibration of the tree model. Colors indicate amount of displacement
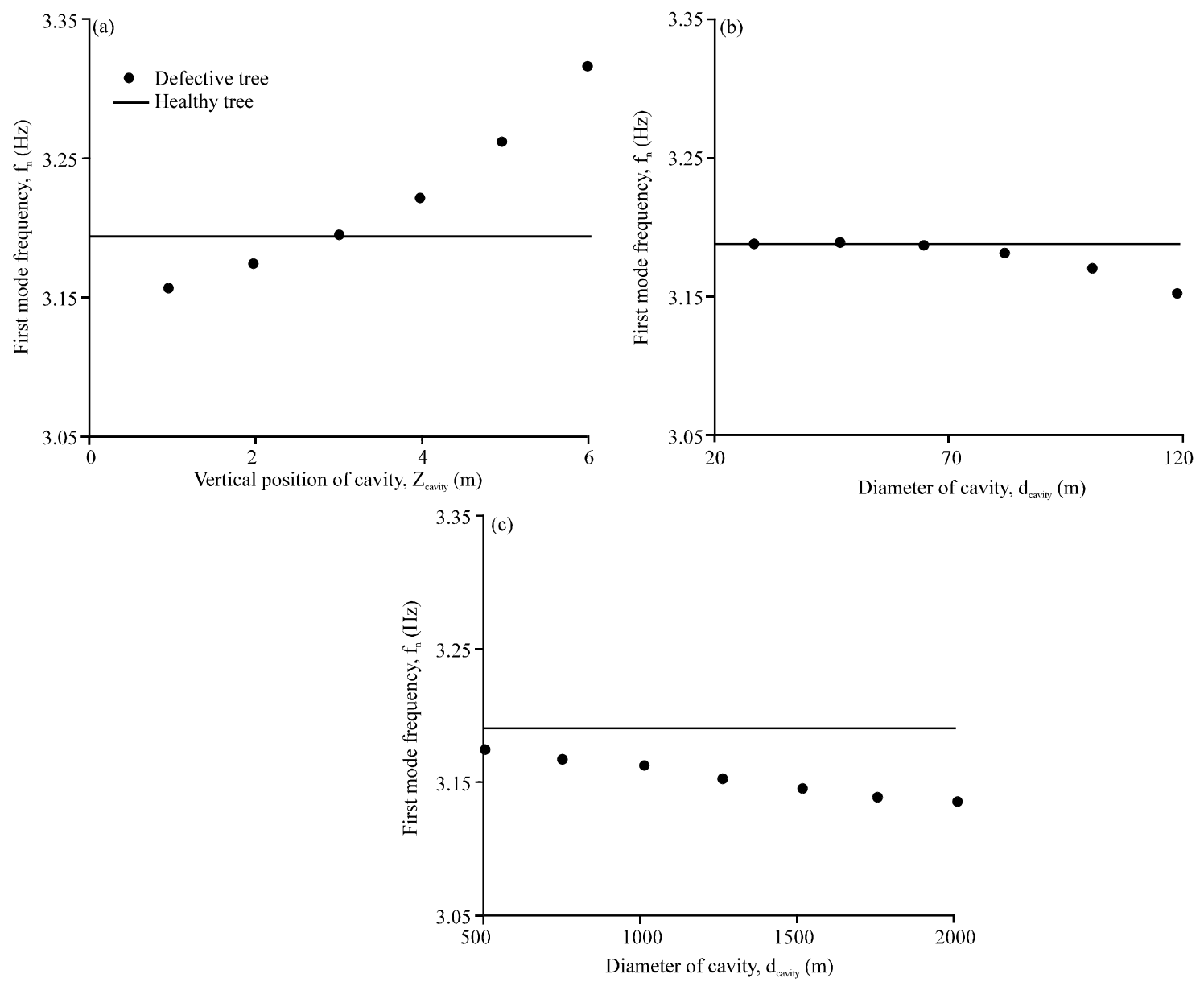

Fig. 5: Graph of the first mode natural frequencies of the tree model with; a) Variation in its vertical position; b) Variation in its diameter and c) Variation in its length

Unlike the second simulation in both the third simulation (diameter of cavity, $\mathrm{d}_{\text {carity }}$ was varied) and the forth simulation (length of cavity, $1_{\text {carity }}$ was varied), the change in natural frequency is observed to only go lower than that of the control value. Both graphs of the results are shown in Fig. 5b, c, respectively. In the third 
simulation, the value of natural frequency gets closer to that of the healthy tree when the diameter of cavity was set closer to zero and the natural frequency gets lower as the diameter gets larger. However, the decrease is arguably lower when the diameter of cavity, $\mathrm{d}_{\text {carity }}$ was set at $130 \mathrm{~mm}$ (or half its $\mathrm{d}_{\text {base }}$ ), the decrease recorded is only $1.19 \%$. The same trend is also observable in the forth simulation as the decrease recorded when the length, $1_{\text {caxity }}$ was set at $2000 \mathrm{~mm}$ is only $1.34 \%$.

From all results shown above, it can be inferred that the existence of a defect such as cavities indeed has been proven to alter the natural frequency. All cases of varieties in cavity's geometry result in either an increase or decrease of natural frequency as compared to that of the healthy tree. A special note, however, shall be given to the case of varied cavity's vertical position as it can go lower and higher than the control value. These findings underline the potential implementation of the proposed method for evaluation of tree's condition in the future.

As additional notes for future implementation, several things have to be considered. First, a clear detection procedure must be developed including the incorporation of possible error in experimental retrieval of data. Second, a thorough actual cases of sophisticated tree's geometry has to be considered, especially, the effect of branches, etc. Third, noticing some small changes in value for several scenarios of defect, a highly sensitive and accurate means of measurement has to be considered. Fourth, other types of defect in a tree may also be considered simultaneously to produce a more robust detection method.

\section{CONCLUSION}

Simulation studies involving four different scenarios have been carried out to learn how the introduction of a cavity to an Enterolobium cyclocarpum tree model will affect its first mode natural frequency. It has been observed that the natural frequency of the simulated tree model with a cylindrical-shaped cavity changes as some geometric parameters of the cavity are varied. Especially, when the vertical position of the cavity is varied, the change in natural frequency value can go higher or lower than that of the healthy tree. On the other hand, when the diameter and length are varied, the value of natural frequency can only go lower. The maximum change in the observed value in this study is approximately $3.9 \%$.

\section{RECOMMENDATIONS}

These results show a good potential for the proposed method to be used for condition monitoring of a tree. However, further studies are needed to practically utilize the data into a working mechanism under real conditions.

\section{ACKNOWLEDGEMENTS}

This research was partially supported by Hibah PTUPT Kemenristekdikti fiscal year 2018 (512/UN2.R3.1/HKP05.00/2018). We are also grateful to the help of Prof. dra. Fatma Lestari, M.Si., Ph.D and Dr. Anom Bowolaksono, MSc. of Occupational Safety, Health and Environmental (OSHE) Unit Universitas Indonesia for their provision of trees data in the campus.

\section{REFERENCES}

Bucur, V., 2003. Techniques for high resolution imaging of wood structure: A review. Meas. Sci. Technol., 14: R1-R91.

Castro-Garcia, S., G.L. Blanco-Roldan and J.A. Gil-Ribes, 2011. Frequency response of Pinus pinea L. for selective cone harvesting by vibration. Trees, 25: 801-808.

Hassinen, A., M. Lemettinen, H. Peltola, S. Kellomaki and B. Gardiner, 1998. A prism-based system for monitoring the swaying of trees under wind loading. Agric. For. Meteorol., 90: 187-194.

Kerzenmacher, T. and B. Gardiner, 1998. A mathematical model to describe the dynamic response of a spruce tree to the wind. Trees, 12: 385-394.

Miles, J.A., J.J. Mehlschau and S. Moini, 1981. Factors affecting harvest of Loblolly pine cones. Trans. ASAE., 24: 323-325.

Milne, R., 1991. Dynamics of swaying of Picea sitchensis. Tree Physiol., 9: 383-399.

Moore, J.R. and D.A. Maguire, 2005. Natural sway frequencies and damping ratios of trees: Influence of crown structure. Trees, 19: 363-373.

Moore, J.R. and D.A. Maguire, 2008. Simulating the dynamic behavior of Douglas-fir trees under applied loads by the finite element method. Tree Physiol., 28: $75-83$.

Pokorny, J., J. O'Brien, R. Hauer, G. Johnson and J. Albers et al., 2003. Urban tree risk management: A community guide to program design and implementation. USDA Forest Service, Washington, D.C., USA. https://www.fs. usda.gov/treesearch /pubs/11070

Sellier, D., T. Fourcaud and P. Lac, 2006. A finite element model for investigating effects of aerial architecture on tree oscillations. Tree Physiol., 26: 799-806.

Socco, L.V., L. Sambuelli, R. Martinis, E. Comino and G. Nicolotti, 2004. Feasibility of ultrasonic tomography for nondestructive testing of decay on living trees. Res. Nondestr. Eval., 15: 31-54. 
Sola-Guirado, R.R., S. Castro-Garcia, G.L. Blanco-Roldan, F. Jimenez-Jimenez and F.J. Castillo-Ruiz et al., 2014. Traditional olive tree response to oil olive harvesting technologies. Biosyst. Eng., 118: 186-193.

Spatz, H.C. and F. Bruechert, 2000. Basic biomechanics of self-supporting plants: Wind loads and gravitational loads on a Norway spruce tree. For. Ecol. Manage., 135: $33-44$.
Telewski, F.W., 1995. Wind-Induced Physiological and Deveop-Mental Responses in Trees. In: Wind and Tree, Coutts M.P. and J. Grace (Eds.). Cambridge University Press, Cambridge, UK., pp: 237-263.

White, R.G., M.F. White and G.J. Mayhead, 1976. Measurement of the Motion of Trees in Two Dimensions. University of Southhampton, Southampton, England, UK.,. 